\title{
Suplementação com concentrado para novilhas de corte mantidas em pastagens cultivadas de estação fria
}

\section{Luciana Pötter ${ }^{1}$, Marta Gomes da Rocha ${ }^{2}$, Dalton Roso ${ }^{3}$, Vagner Guasso da Costa ${ }^{3}$, Carine Lisete Glienke ${ }^{3}$, Aline Nunes da Rosa ${ }^{4}$}

\author{
1 Programa Pós-graduação em Zootecnia, Universidade Federal de Santa Maria - UFSM, RS/Departamento de Zootecnia CESNORS - Palmeira \\ das Missões, RS. \\ 2 Departamento de Zootecnia, Universidade Federal de Santa Maria, RS. Pesquisador CNPq \\ 3 Programa de pós-graduação em Zootecnia, Universidade Federal de Santa Maria - UFSM. \\ ${ }^{4}$ Curso de Graduação em Zootecnia, Universidade Federal de Santa Maria, RS.
}

RESUMO - Com o objetivo de avaliar as relações não-aparentes em estudos individuais foram analisadas em conjunto variáveis provenientes de nove experimentos realizados com diversos níveis e tipos de suplementos para novilhas de corte em pastagens cultivadas de estação fria. Os dados foram estratificados em dois grupos: com e sem suplemento concentrado. A massa de forragem e a oferta de lâminas foliares, assim como a estrutura do dossel (altura e relação folha:colmo), foram semelhantes entre os grupos com e sem suplementação. As novilhas que receberam suplemento consumiram pasto com menor teor de fibra em detergente neutro e apresentaram maior ganho médio diário. A suplementação aumentou em 33,3\% o consumo total de matéria seca. Para cada kg consumido de MS do concentrado, o consumo de MS do pasto reduziu 0,7 kg. A eficiência de transformação da forragem foi semelhante entre os grupos com ou sem suplementação, com valor médio de 9,5 kg de MS da forragem $/ \mathrm{kg}$ de peso corporal ganho. As novilhas que receberam suplemento ingeriram $6,4 \mathrm{~kg}$ de MS do suplemento a cada kg de ganho adicional. O uso de suplemento concentrado permitiu o aumento da taxa de lotação e do ganho de peso por área. Novilhas sob suplementação com concentrado apresentam maiores pesos corporais, maiores alturas de cernelha e maiores escores de condição corporal no final do período de utilização da pastagem.

Palavras-chave: Avena strigosa, desempenho animal, Lolium multiflorum, substituição, taxa de lotação

\section{Concentrate supplementation for beef heifers on cool-season cultivated pastures}

\begin{abstract}
In order to evaluate not apparent relationships in individual studies, variables measured in nine experiments were analyzed in set. These experiments tested levels and sources of supplement for beef heifers, on cool-season cultivated pasture. Data were stratified in two groups: with and without concentrate supplementation. Forage mass and leaf blades on offer as well as sward structure (height and leave:stem ratio) were similar for both groups. Supplemented heifers consumed forage with lesser neutral detergent fiber levels and presented higher average daily gain. Supplementation increased total dry matter intake by $33.3 \%$. For each eaten $\mathrm{kg}$ of dry matter concentrate, the grass dry matter intake decreased in $0.7 \mathrm{~kg}$. The efficiency of transformation of the forage was similar for both groups, with an average value of $9.5 \mathrm{~kg}$ of dry matter of forage $/ \mathrm{kg}$ of gained body weight. Heifers that received supplement ingested $6.4 \mathrm{~kg}$ of supplement dry matter for each additional $\mathrm{kg}$ of added gain. The utilization of concentrate supplements provided an increment on stocking rate and weight gain/area. Heifers fed concentrate supplements present greater body weight, height, and body condition score at the end of the pasture utilization period.
\end{abstract}

Key Words: animal performance, Avena strigosa, Lolium multiflorum, stocking rate, substitution

\section{Introdução}

Os custos e o manejo exigido em experimentos a campo, com animais em pastejo, limitam o número de tratamentos explorados em cada trabalho. Assim, com vários níveis e tipos de suplementos para fêmeas bovinas de corte, foram conduzidos trabalhos na Universidade
Federal de Santa Maria para estudar a relação animal/ suplemento/pastagem de clima temperado (Rocha et al., 2007).

A importância do uso de suplementos para bovinos de corte no Rio Grande do Sul, deve-se, em parte, ao crescimento de $12 \%$ nos últimos dez anos da área de lavouras de verão (IBGE, 2007) e que teve como conseqüências para a pecuária, a redução na área pastoril e o aumento da disponibilidade 
de subprodutos que podem ser utilizados na alimentação de ruminantes. A suplementação é uma alternativa para atenuar as variações na produção de forragem ao longo da estação de pastejo ou mesmo nos anos (Elizalde, 2003) e cumpre o objetivo de suprir um déficit em quantidade ou qualidade da forragem e/ou aumento da taxa de lotação e ganho médio diário (Horn et al., 2005).

A idade ao primeiro acasalamento de fêmeas bovinas é uma medida importante de eficiência reprodutiva do rebanho. Exclusivamente em campo nativo, no Rio Grande do Sul, as novilhas têm idade média de 27,8 meses ao início do primeiro acasalamento. A tomada de decisões sobre a alimentação dessa categoria condiciona a idade-meta para o seu primeiro parto: 36, 27 ou 24 meses de idade. A idadealvo a alcançar depende do peso à desmama, do peso-alvo a atingir e, portanto, da taxa de ganho no período compreendido entre a desmama e o acasalamento.

O uso de suplementos pode favorecer o ganho de peso e o aumento da taxa de lotação, permitindo que, simultaneamente maior número de fêmeas esteja pronto para o acasalamento. Além do peso, o valor mínimo de três no escore de condição corporal das fêmeas, no início da estação de monta, assegura a manifestação da puberdade (Rice, 1991). Para isso, o uso de suplementos melhora a deposição de gordura por alterar a composição do ganho de peso (Lemenager et al., 1980) e resulta em “superávit” energético destinado às funções reprodutivas.

Com o objetivo de avaliar relações não aparentes nos estudos individuais, as variáveis medidas e analisadas oriundas de nove experimentos, sobre os níveis e tipos de suplementos na recria de fêmeas bovinas de corte foram organizadas e analisadas em conjunto, permitindo providenciar um conjunto de informações mais acuradas sobre o uso de suplementos em pastagens cultivadas de clima temperado.

\section{Material e Métodos}

Os dados utilizados referem-se a 360 observações procedentes de nove experimentos realizados no setor de forragicultura do Departamento de Zootecnia da Universidade Federal de Santa Maria (UFSM), entre os anos de 1999 e 2007 (Tabela 1). Nos experimentos foi avaliada a recria de fêmeas bovinas de corte em pastagens cultivadas de estação fria recebendo suplemento concentrado ou exclusivamente em pastejo e constituíram a base de dados denominada 'Pastos\&Suplementos'. As variáveis mensuradas nos experimentos foram estratificadas conforme a ausência ou presença de suplemento e submetidas ao teste de homogeneidade das variâncias entre os grupos por meio do procedimento General Linear Model (GLM) do programa estatístico Statistical Analysis System - SAS (SAS, 2001). Para eleger as variáveis a serem incluídas no trabalho, foi analisado o quadrado médio do erro experimental (QME) dos grupos utilizando somente aquelas cuja relação entre os QME foi inferior a 7:1 (Coimbra et al., 2004).

Tabela 1 - Relação cronológica dos estudos da base de dados ‘Pastos\&Suplementos’ com os dias de utilização da terra, caracterização dos suplementos concentrados e referências bibliográficas

\begin{tabular}{|c|c|c|c|c|c|}
\hline Estudo & Ano & Dias & \multicolumn{2}{|c|}{ Suplemento concentrado } & Referências \\
\hline 1 & 1999 & 195 & 0,$0 ; 0,7 ; 1,4$ & Farelo de arroz+polpa cítrica & $\begin{array}{l}\text { Frizzo et al. (2003a) } \\
\text { Frizzo et al. (2003b) }\end{array}$ \\
\hline 2 & 2000 & 183 & 1,0 & Grão de sorgo & $\begin{array}{l}\text { Rocha et al. (2003) } \\
\text { Rocha et al. (2004) }\end{array}$ \\
\hline 3 & 2001 & 151 & 0,9 & Grão de milho ou casca de soja & $\begin{array}{l}\text { Santos et al. (2004) } \\
\text { Santos et al. (2005) }\end{array}$ \\
\hline 5 & 2002 & 178 & 0,$0 ; 0,5 ; 1,0 ; 1,5$ & Farelo de trigo & $\begin{array}{l}\text { Pilau et al. (2004) } \\
\text { Bremm et al. (2005) }\end{array}$ \\
\hline 6 & 2003 & 176 & 0,$0 ; 0,3 ; 0,6 ; 0,9 ; 1,2 ; 1,5$ & Farelo de trigo & $\begin{array}{l}\text { Freitas et al. (2005a) } \\
\text { Freitas et al. (2005b) } \\
\text { Bremm et al. (2008) }\end{array}$ \\
\hline
\end{tabular}

${ }^{1}$ Produto comercial com $30 \%$ de amido e $60 \%$ de fibra solúvel. 
Os experimentos envolveram 608 novilhas de corte, com idade inicial entre 7 e 9 meses, resultantes em quase sua totalidade de produtos do cruzamento da raça Charolês com Nelore em diferentes graus de sangue. O peso médio desses animais ao início da utilização das pastagens de inverno foi de $161,17 \pm 8,86 \mathrm{~kg}$.

Os experimentos foram conduzidos na região fisiográfica denominada Depressão Central do Rio Grande do Sul, com altitude de $95 \mathrm{~m}$, latitude $29^{\circ} 43^{\prime}$ Sul e longitude $53^{\circ} 42^{\prime}$ Oeste. O clima da região é Cfa (subtropical úmido), conforme classificação de Köppen. As pastagens foram estabelecidas em solo classificado como argissolo vermelho distrófico arênico. Os dados médios da análise química do solo no início dos estudos foram: $\mathrm{pH}$ em água: 5,2 ; cálcio4,8 $\mathrm{cmol}_{\mathrm{C}} / \mathrm{dm}^{3}$; magnésio - 3,0 $\mathrm{cmol}_{\mathrm{C}} / \mathrm{dm}^{3}$; alumínio - 0,5 $\mathrm{cmol}_{c} / \mathrm{dm}^{3}$; capacidade de troca catiônica efetiva $-9,0 \mathrm{cmol}_{\mathrm{C}} / \mathrm{dm}^{3}$; matéria orgânica-2,8\%; fósforo - 7,7 mg/dm³ e potássio - 53,6 mg/dm³ . As adubações realizadas nas áreas dos experimentos seguiram as recomendações de adubação e calagem para os estados do Rio Grande do Sul e Santa Catarina (ROLAS, 1994). Em todos os experimentos, a adubação foi realizada com N-P-K, utilizando-se as fórmulas 05-20-20, 07-10-10 e 10-20-10 em quantidades de 200 a $300 \mathrm{~kg} / \mathrm{ha}$ de adubo.

As pastagens foram constituídas de aveia-preta (Avena strigosa Schreb.), azevém (Lolium multiflorum Lam.), trevo-vesiculoso (Trifolium vesiculosum Savi) e trevovermelho (Trifolium pratense, cv. LE 116). O método de pastejo foi o de lotação contínua, com número variável de animais reguladores para manter a massa de forragem em $1.500 \mathrm{~kg} / \mathrm{ha}$ de MS. O número de animais testadores foi de três por repetição de área em todos os experimentos e o número de piquetes utilizados como repetição de área em cada tratamento variou de 2 a 4 .

As variáveis referentes ao pasto e à pastagem foram: massa de forragem, taxa de acúmulo de forragem, oferta de forragem, oferta de forragem + suplemento, relação folha:colmo, oferta de lâminas foliares e altura do dossel. As metodologias utilizadas para obtenção das variáveis referentes ao pasto e a pastagem estão descritas em Freitas et al. (2005ab).

Na forragem aparente consumida, obtida por simulação de pastejo, foram determinados os teores de matéria seca (MS), proteína bruta, segundo a AOAC (1995), a digestibilidade in vitro da matéria orgânica (DIVMO), de acordo com Tilley \& Terry (1963), e de fibra em detergente neutro, segundo Goering \& Van Soest (1970). O teor de nutrientes digestíveis totais foi calculado pelo produto entre a porcentagem de matéria orgânica e a DIVMO, dividido por 100. As informações coletadas nos animais foram: ganho médio diário, peso corporal, escore de condição corporal e altura da garupa. As informações obtidas por unidade de área foram taxa de lotação e ganho de peso por área. As variáveis coletadas nos animais e por unidade de área seguiram metodologias descritas por Frizzo et al. (2003ab).

O período de utilização da terra compreendeu a ocupação da área desde a semeadura até o final do ciclo do pastejo, com número médio de 60 dias para o estabelecimento e 110 dias para utilização. Os níveis de suplemento utilizados variaram de 0 a 1,5\% da matéria seca em relação ao peso corporal, com valor médio de $0,9 \%$.

Para o cálculo do consumo estimado de matéria seca, foram subtraídas da produção total de MS/ha a forragem disponível no final do período experimental e as perdas de forragem durante o período de pastejo. Dividindo o consumo estimado de MS/ha pela taxa de lotação média, obteve-se o consumo estimado de matéria seca em porcentagem do peso corporal.

No cálculo da taxa de adição e do coeficiente de substituição do consumo de suplemento sobre o consumo de forragem (Hodgson, 1990), os valores de consumo foram apenas descritivos, ou seja, não foi realizada análise estatística. As fórmulas utilizadas foram: coeficiente de substituição $=[$ (consumo de matéria seca (MS) de forragem dos animais sem suplementação menos o consumo de MS daqueles que receberam suplemento)/consumo de MS do suplemento; taxa de adição $=[$ (consumo total de MS dos animais sob suplementação menos o consumo de MS da forragem dos animais que não receberam suplemento)/ consumo de matéria seca do suplemento]*100.

A eficiência de transformação da forragem consumida em peso corporal foi obtida pela razão entre a forragem desaparecida e o ganho de peso por área. A eficiência de transformação de kg de suplemento em peso corporal foi obtida pela razão entre a quantidade de suplemento fornecida aos animais e o ganho de peso adicional por área em relação ao uso exclusivo da pastagem.

Para comparar os grupos com e sem suplemento, as variáveis provenientes de 'Pastos\&Suplementos' que apresentaram homogeneidade de variância foram submetidas à análise de variância dos dados e ao teste F. As análises foram feitas utilizando-se procedimento GLM do programa estatístico SAS versão 8.2 (SAS, 2001).

\section{Resultados e Discussão}

Todas as relações entre as variâncias residuais não excederam o valor de 7:1, indicaram condição de homocedasticidade entre os grupos em estudo (Coimbra et al., 2004) (Tabela 2). 
Tabela 2 - Quadrado médio do erro para as variáveis estudadas em 'Pastos\&Suplementos' nos grupos de novilhas com e sem suplemento

\begin{tabular}{|c|c|c|c|}
\hline \multirow[b]{2}{*}{ Variável estudada } & \multicolumn{2}{|c|}{$\begin{array}{l}\text { Quadrado médio } \\
\text { do erro (QME) }\end{array}$} & \multirow{2}{*}{$\begin{array}{c}\text { Relação } \\
\text { entre } \\
\text { os QME }\end{array}$} \\
\hline & $\begin{array}{c}\text { Com } \\
\text { suplemento }\end{array}$ & $\begin{array}{c}\text { Sem } \\
\text { suplemento }\end{array}$ & \\
\hline Massa de forragem & $33.738,93$ & $31.244,66$ & 1,08 \\
\hline $\begin{array}{l}\text { Taxa de acúmulo } \\
\text { de forragem }\end{array}$ & 185,72 & 277,98 & 1,50 \\
\hline $\begin{array}{l}\text { Oferta de forragem } \\
\text { Oferta de }\end{array}$ & 3,96 & 2,42 & 1,64 \\
\hline forragem + suplemento & 3,63 & 2,42 & 1,50 \\
\hline Relação folha:colmo & 0,43 & 0,11 & 3,91 \\
\hline Oferta de lâminas foliares & 1,28 & 0,69 & 1,86 \\
\hline Altura do dossel & 4,41 & 3,62 & 1,22 \\
\hline $\begin{array}{l}\text { Teor de proteína bruta } \\
\text { Digestibilidade }\end{array}$ & 2,20 & 2,44 & 1,10 \\
\hline $\begin{array}{l}\text { in vitro da matéria orgânica } \\
\text { Teor de fibra em }\end{array}$ & 22,32 & 15,78 & 1,41 \\
\hline detergente neutro & 47,61 & 14,90 & 3,20 \\
\hline Ganho médio diário & 0,03 & 0,03 & 1,00 \\
\hline Taxa de lotação & 0,70 & 0,35 & 2,00 \\
\hline Ganho de peso por área & 3,87 & 1,56 & 2,48 \\
\hline Peso corporal inicial & 138,63 & 126,90 & 1,09 \\
\hline Peso corporal final & 230,92 & 134,49 & 1,72 \\
\hline Escore de condição corporal & 0,02 & 0,01 & 2,00 \\
\hline Altura inicial das novilhas & 1,17 & 4,77 & 4,08 \\
\hline $\begin{array}{l}\text { Altura final das novilhas } \\
\text { Relação peso }\end{array}$ & 2,28 & 1,68 & 1,36 \\
\hline $\begin{array}{l}\text { corporal:altura inicial } \\
\text { Relação peso }\end{array}$ & 0,01 & 0,01 & 1,00 \\
\hline corporal:altura final & 0,06 & 0,01 & 6,00 \\
\hline
\end{tabular}

Os teores de matéria seca (MS), proteína bruta e fibra em detergente neutro caracterizam a forragem como de alta qualidade (Figura 1), pois, conforme Clark \& Kanneganti (1998), pastagens cultivadas de estação fria, jovens e com elevada quantidade de folhas, são caracterizadas por valores entre 18 a 24\% de matéria seca, 18 a $25 \%$ de proteína bruta, 40 a 50\% de fibra em detergente neutro e 1,53 a 1,67 Mcal/kg de matéria seca. O teor de matéria seca da forragem não limitou o consumo, pois foi superior a 18\%, considerado limitante por Alberto (1997). O teor de proteína bruta preconizado pelo NRC (1996) para atender às exigências em proteína bruta de novilhas de corte com peso corporal (PC) médio de $200 \mathrm{~kg}$ e ganho de $918 \mathrm{~g} /$ dia é de 12,1\%. O teor de proteína bruta da pastagem (Figura 1) excedeu em 58,7\% a recomendação do NRC (1996), mas podem ocorrer perdas de 40 a $45 \%$ do total do nitrogênio ingerido em pastagem de azevém (Beever et al., 1985).

As digestibilidades in vitro da matéria orgânica do pasto e do suplemento foram semelhantes $(\mathrm{P}>0,05)$ e permitem alta velocidade de passagem do alimento e máxima ingestão de matéria seca (Bargo et al., 2003). Então, é

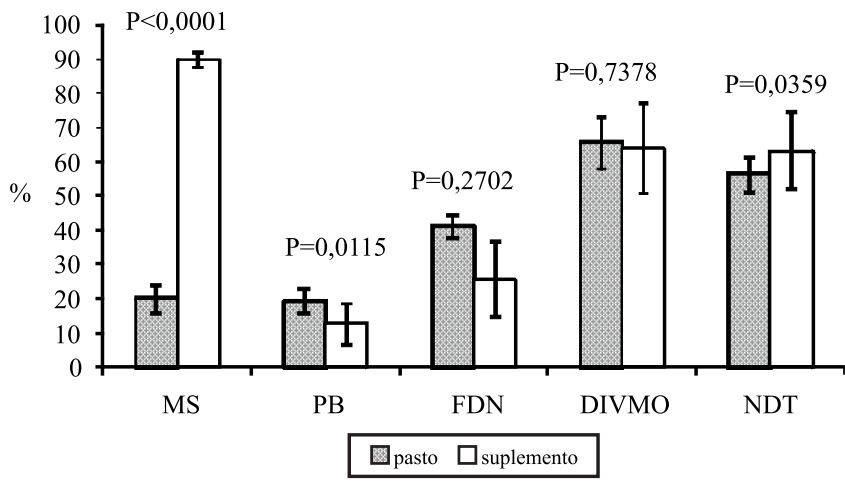

MS= matéria seca; $\mathrm{PB}=$ proteína bruta; FDN = fibra em detergente neutro; $\mathrm{DIVMO}=$ digestibilidade in vitro da matéria orgânica; NDT = nutrientes digestíveis totais; $\mathrm{P}=$ probabilidade no teste $\mathrm{F}$.

Figura 1 - Composição química, digestibilidade in vitro da matéria orgânica e teor de nutrientes digestíveis totais do pasto e dos suplementos.

metabólico o mecanismo que regula o consumo voluntário de matéria seca, e não físico (Dixon \& Stockdale, 1999). Os valores de fibra em detergente neutro, digestibilidade in vitro da matéria orgânica e nutrientes digestíveis totais (NDT) do suplemento permitem caracterizá-lo como concentrado energético (NRC, 1996).

As variáveis massa de forragem, taxa de acúmulo de forragem, oferta de forragem + suplemento, relação folha:colmo, oferta de lâminas foliares, altura do dossel, teor de proteína bruta e digestibilidade in vitro da matéria orgânica foram semelhantes entre os grupos com e sem suplemento ( $\mathrm{P}>0,05$; Tabela 3 ). A maioria dos aspectos mensurados na pastagem foram semelhantes e, portanto, os efeitos no ganhos de peso, na altura dos animais e na condição corporal são atribuídos ao maior consumo de energia e nutrientes pelos os animais sob suplementação com concentrado.

Novilhas que receberam suplemento consumiram pasto com menor teor de fibra em detergente neutro $(\mathrm{P}<0,05)$ (Tabela 3$)$. Entre os componentes estruturais do pasto, as folhas possuem menor teor de fibra em detergente neutro que os caules ou colmos das plantas forrageiras (Van Soest, 1994), o que sugere que animais sob suplementação foram mais seletivos e consumiram mais folhas.

O manejo da pastagem deve prever oferta de forragem que eleve o consumo de matéria seca da forragem, como descrito por St-Pierre (2001), que descreveu uma regressão quadrática entre estimativa do consumo de matéria seca da forragem e oferta de forragem. Segundo Gibb \& Treacher (1976), ruminantes em pastejo necessitam de oferta de forragem três vezes e meia maior que seu consumo máximo de MS. Para bovinos que recebem 
suplemento, no entanto, a oferta de forragem não deve exceder duas vezes a estimativa de ingestão de MS (Bargo et al., 2003). A oferta de forragem observada para as novilhas de grupos com e sem suplemento, mesmo com valores diferentes $(\mathrm{P}<0,05)$, superam os valores recomendados por Bargo et al. (2003). A oferta de lâminas foliares excede em 1,1\% o consumo de MS previsto pelo NRC (1996) para a categoria de novilhas estudadas, confirmando que os animais não sofreram restrição ao consumo de pasto.

A variabilidade dos parâmetros incluídos no cálculo da estimativa de consumo de MS adotando-se a técnica do desaparecimento de forragem (Astigarraga, 1997) pode explicar por que os valores de consumo obtidos (Tabela 4) encontram-se acima do valor de $2,5 \%$ do PC preconizado pelo NRC (1996). O consumo de matéria seca, pela técnica utilizada, pode ter sido superestimado por erros na estimativa de produção de forragem inicial e final, pisoteio, atividade de insetos e consumo por animais nãoexperimentais (Minson, 1990).

O coeficiente de substituição observado (Tabela 4) encontra-se dentro do esperado para forrageiras de ciclo hibernal, de 0,5 a $1,0 \mathrm{~kg}$ de pasto substituído por $\mathrm{kg}$ de suplemento ingerido (French et al., 2001b). Quando o coeficiente de substituição do consumo de suplemento sobre o consumo de forragem é menor ou igual a $1 \mathrm{~kg}$, o consumo total de MS é maior nos animais sob suplementação, o que determina maior desempenho individual pelo aumento na ingestão de MS (Bargo et al., 2003). Beever \& Thorp (1997) explicam por que os animais sob suplementação consomem maior quantidade de MS, o que caracteriza o efeito aditivo do consumo de suplemento sobre o consumo de pasto: menor consumo de água associada ao pasto; menor tempo de retenção da digesta no rúmen e redução nas restrições físicas existentes quando o consumo é exclusivo de pasto. Além da saciedade física ou de fatores associados à distensão do aparelho digestivo, a ingestão de MS por animais exclusivamente a pasto pode ser afetada pelo suprimento das exigências nutricionais e limitações comportamentais ou limites ao consumo potencial de pasto resultantes da combinação pasto $\times$ herbívoro, que interferem no comportamento de pastejo (Hodgson \& Brookes, 1999).

Não foram detectadas diferenças na eficiência de transformação da forragem, em kg de peso corporal, para os grupos estudados $(\mathrm{P}>0,05)$, mesmo que alguns trabalhos comprovem maior eficiência na transformação do pasto quando os animais recebem suplemento (Caton \& Dhuyvetter, 1997), atribuído provavelmente ao maior equilíbrio entre os nutrientes (Moore et al., 1999). A eficiência de transformação do suplemento em kg de ganho de peso corporal adicional por hectare foi semelhante aos resultados de 5-8 kg (Elizalde, 2003). Admitindo-se os valores de eficiência de conversão dos suplementos estudados, o preço máximo a ser pago pelo suplemento equivaleria a $15,6 \%$ do preço do $\mathrm{kg}$ vivo de boi. As respostas à utilização de suplementos sob pastejo, no entanto, devem ser analisadas dentro de um contexto mais amplo que ultrapasse a simples conversão de grão em carne bovina durante o período de fornecimento do grão (Elizalde, 2003), que possibilite maior taxa de lotação, maior disponibilidade de superfície para agricultura e redução na idade do primeiro acasalamento e ou abate. Quando analisados os ganhos indiretos com a prática de suplementação, as respostas podem chegar a aumento da eficiência de utilização do grão de 20 a 30\% (Elizalde, 2003).

As exigências de proteína são supridas com o consumo exclusivo de pasto e somente $80 \%$ das exigências energéticas (NDT). Mesmo com a redução no consumo de matéria seca, provocada pelo efeito de substituição do consumo de suplemento, as exigências de proteína foram atendidas pelo pasto (Tabela 5). Em novilhas que receberam suplemento, para determinação da ingestão total de matéria seca, foi aplicado o coeficiente de substituição

Tabela 3 - Atributos da pastagem e do pasto nos grupos com e sem suplementação

\begin{tabular}{|c|c|c|c|c|c|}
\hline \multirow[t]{2}{*}{ Item } & \multicolumn{2}{|c|}{ Suplemento } & \multirow[t]{2}{*}{$\mathrm{N}^{1}$} & \multirow[t]{2}{*}{$\mathrm{CV}, \%$} & \multirow[t]{2}{*}{$\mathrm{P}$} \\
\hline & Com & Sem & & & \\
\hline Massa de forragem & $1.467,7$ & $1.444,2$ & 360 & 12,3 & 0,5357 \\
\hline Taxa de acúmulo de forragem & 47,7 & 46,4 & 359 & 31,5 & 0,5711 \\
\hline Oferta de forragem & 8,8 & 10,0 & 361 & 20,0 & 0,0056 \\
\hline Oferta de forragem + suplemento & 9,7 & 10,0 & 361 & 18,2 & 0,2064 \\
\hline Relação folha:colmo & 1,2 & 1,2 & 229 & 45,7 & 0,9681 \\
\hline Oferta de laminas foliares & 3,5 & 3,8 & 277 & 28,1 & 0,3105 \\
\hline Altura do dossel & 16,6 & 16,0 & 188 & 12,3 & 0,6189 \\
\hline Teor de proteína bruta & 19,2 & 19,4 & 352 & 7,9 & 0,2115 \\
\hline Teor de digestibilidade in vitro da matéria orgânica & 61,6 & 63,0 & 279 & 7,3 & 0,4561 \\
\hline Teor de fibra em detergente neutro & 40,4 & 42,5 & 129 & 15,4 & 0,0004 \\
\hline
\end{tabular}

${ }^{1}$ Número de observações; CV = Coeficiente de variação; $\mathrm{P}=$ Probabilidade no teste $\mathrm{F}$. 
de $0,7 \mathrm{~kg}$ de matéria seca do pasto/kg de matéria seca do suplemento.

Quando os animais permaneceram exclusivamente em pastagem, ingeriram 357,1 g de proteína bruta por kg de nutrientes digestíveis totais, enquanto as novilhas que receberam suplemento ingeriram 281,2 g de proteína bruta por kg de nutrientes digestíveis totais, valores bem acima da recomendação do NRC (1996) para esta categoria, de $171,4 \mathrm{~g}$ de $\mathrm{PB} / \mathrm{kg}$ de nutrientes digestíveis totais, caracterizando maior ingestão de nitrogênio em relação à energia disponível na dieta, principalmente para aqueles animais que permaneceram exclusivamente em pastagem (Moore et al., 1999).

Com a aplicação da taxa de substituição no valor de consumo estimado pelo NRC (1996), as novilhas que receberam suplemento ingeriram $8,9 \mathrm{~g}$ FDN/kg de peso corporal, enquanto aquelas exclusivamente a pasto colheram em média 10,4 g FDN/kg de peso corporal, abaixo do valor de 12,0 g FDN/kg peso corporal, sugerido por Mertens (1992) como ponto máximo para que não ocorra redução no consumo de pasto. A seleção do pasto com menor teor de fibra em detergente neutro por novilhas sob

Tabela 4 - Estimativa de consumo de matéria seca, coeficiente de substituição, taxa de adição, eficiência de transformação do pasto e do suplemento

\begin{tabular}{lcc}
\hline Item & $\begin{array}{c}\text { Sem } \\
\text { suplemento }\end{array}$ & $\begin{array}{c}\text { Com } \\
\text { suplemento }\end{array}$ \\
\hline $\begin{array}{l}\text { Consumo MS do pasto, } \\
\text { \% do peso corporal (PC) }\end{array}$ & 3,0 \\
$\begin{array}{l}\text { Consumo MS do pasto + } \\
\text { suplemento (\% do PC) }\end{array}$ & - & 0,9 \\
$\begin{array}{l}\text { Coeficiente de substituição (kg) } \\
\text { Taxa de adição (\%) }\end{array}$ & - & 0,7 \\
$\begin{array}{l}\text { Eficiência de transformação } \\
\text { do pasto (kg) }\end{array}$ & - & 33,3 \\
$\begin{array}{l}\text { Eficiência de transformação } \\
\text { do suplemento (kg) }\end{array}$ & $10,3 \pm 2,9$ & $9,0 \pm 3,7$ ns \\
\hline
\end{tabular}

$\mathrm{ns}=$ não-significativo - teste $\mathrm{F}(\mathrm{P}>0,05)$.

Tabela 5 - Exigências de matéria seca, proteína bruta e nutrientes digestíveis totais de novilhas de corte e contribuições nutricionais do pasto e do suplemento

\begin{tabular}{lccc}
\hline Fração & $\begin{array}{c}\text { Matéria } \\
\text { seca }\end{array}$ & $\begin{array}{c}\text { Proteína } \\
\text { bruta }\end{array}$ & $\begin{array}{c}\text { Nutrientes } \\
\text { digestíveis } \\
\text { totais }\end{array}$ \\
\hline $\begin{array}{l}\text { Exigências, kg/dia } \\
\begin{array}{l}\text { Fornecido pelo } \\
\text { pasto - sem substituição }\end{array}\end{array}$ & 5,0 & 0,6 & 3,5 \\
$\begin{array}{l}\text { Fornecido pelo } \\
\text { pasto - com substituição }\end{array}$ & 5,0 & 1,0 & 2,8 \\
$\begin{array}{l}\text { Fornecido pelo suplemento } \\
\text { Fornecido pelo }\end{array}$ & 1,8 & 0,7 & 2,1 \\
pasto + suplemento & 5,6 & 0,9 & 1,1 \\
\hline
\end{tabular}

suplementação (Tabela 3) também pode explicar parcialmente seu maior desempenho, pois, conforme Van Soest (1994), o consumo é inversamente proporcional ao teor de fibra em detergente neutro no pasto, atribuído principalmente ao maior tempo para esvaziamento do rúmen.

Nas novilhas que receberam suplemento, o ganho médio diário foi 22,5\% maior que naquelas exclusivamente em pastagem $(\mathrm{P}<0,05)$ (Tabela 6$)$. Esse maior ganho é explicado pelo aumento na ingestão de matéria seca e nutrientes, especialmente energia. Essa afirmação é confirmada pelo efeito aditivo verificado (Tabela 4), o que torna possível trabalhar com a hipótese de que a energia proveniente do pasto tenha sido maior para as novilhas que receberam suplemento, pois estas colheram o pasto com menor teor de fibra em detergente neutro.

É improvável que a ação do suplemento em aumentar o ganho médio diário esteja relacionada a maior digestibilidade da dieta, pois os suplementos apresentaram digestibilidade in vitro da matéria orgânica semelhante $(\mathrm{P}>0,05)$ à do pasto (Figura 2). A contribuição do suplemento na dieta total foi de $31,6 \%$ e para percentuais semelhantes a este, não foram observadas diferenças na digestibilidade da matéria seca da dieta. Em pesquisas realizadas por French et al., (2001a), os autores relatam ainda que a digestibilidade total da dieta pode aumentar quando os animais recebem suplemento e a oferta de pasto é baixa. Poppi \& McLennan (1995) também afirmaram que o uso de suplementos em pastagens de alta qualidade permite corrigir dietas desbalanceadas, retendo mais energia e proporcionando melhora no ambiente ruminal e no aproveitamento dos nutrientes.

O baixo conteúdo de carboidratos solúveis, associado à elevada concentração de proteína degradada no rúmen, caracteriza as pastagens temperadas de alta qualidade (Horn et al., 2005). Consequentemente, maiores taxas de uréia são excretadas, provocando balanço energético negativo no animal. $\mathrm{O}$ uso de suplementos energéticos nestas situações é capaz de restaurar o balanço ruminal

Tabela 6 - Desempenho de novilhas de corte em 'Pastos \& Suplementos'

\begin{tabular}{|c|c|c|c|c|c|}
\hline \multirow[b]{2}{*}{ Item } & \multicolumn{2}{|c|}{ Suplemento } & \multirow[b]{2}{*}{$n^{1}$} & \multirow[b]{2}{*}{$\mathrm{CV}, \%$} & \multirow[b]{2}{*}{$\mathrm{P}$} \\
\hline & Sem & Com & & & \\
\hline Ganho médio diário, g & 766,5 & 938,8 & 360 & 20,3 & 0,0077 \\
\hline $\begin{array}{l}\text { Taxa de lotação, UA/ha } \\
\text { Ganho de peso por }\end{array}$ & 2,4 & 3,0 & 360 & 15,1 & 0,0059 \\
\hline área, kg/ha/dia & 4,1 & 5,9 & 360 & 16,8 & 0,0011 \\
\hline
\end{tabular}

${ }^{1}$ Número de observações; $\mathrm{CV}=$ Coeficiente de variação; $\mathrm{P}=$ Probabilidade no teste $\mathrm{F}$.

$\mathrm{UA}=$ Unidade animal. 

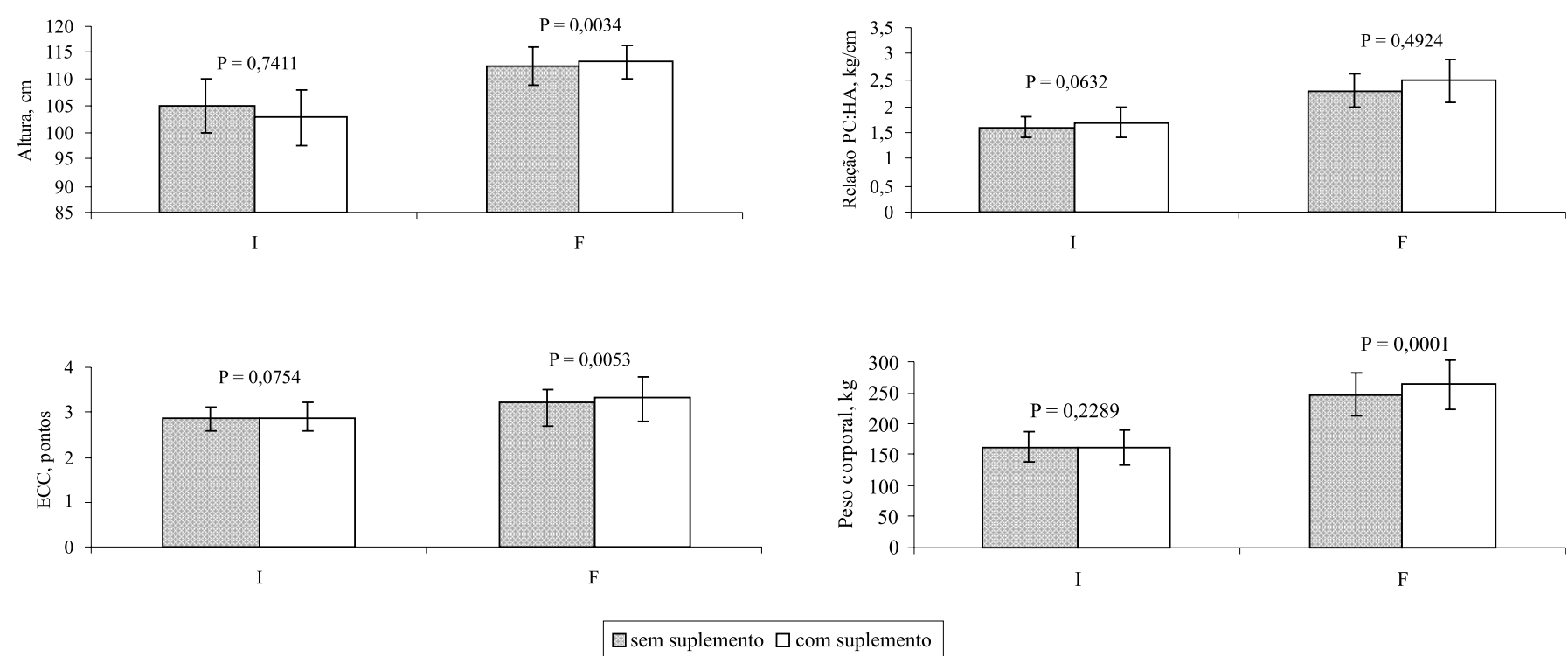

Figura 2 - Altura, relação peso corporal:altura (PC:HA), escore de condição corporal (ECC) e peso corporal ao início (I) e final (F) do período de utilização da pastagem hibernal para novilhas de corte com e sem suplemento.

entre nitrogênio degradado e energia fermentada, otimizando o ambiente ruminal para capturar o nitrogênio degradado e oferecendo maior oportunidade de melhorar o desempenho que mudanças na disponibilidade do pasto (French et al., 2001a).

O coeficiente de substituição calculado correspondeu a um aumento de $25,0 \%(P<0,05)$ na taxa de lotação. O uso de suplementos permite manter a taxa de lotação no decorrer do ciclo da pastagem, mesmo em períodos de menor crescimento do pasto (Fernández \& Mieres, 2005). A viabilidade do uso de suplementos relaciona-se ao custo adicional por kg de suplemento fornecido, considerando que a base forrageira é um alimento de menor custo.

Com o uso de suplemento, o ganho de peso por área foi $43,9 \%$ superior ao uso exclusivo da pastagem, como reflexo do maior ganho de peso individual e da maior taxa de lotação observada (Tabela 6). O ganho de peso por área é o componente decisório na determinação da renda obtida no sistema pecuário mesmo quando o objetivo final não é o abate dos animais. Maior ganho de peso por área num sistema cujo objetivo é a redução da idade ao primeiro acasalamento pode indicar maior eficiência de utilização das pastagens e/ou maior número de novilhas atingindo o peso-alvo por ocasião do primeiro acasalamento.

Ao início do experimento os animais não apresentaram diferença $(\mathrm{P}>0,05)$ no peso corporal, altura e no escore de condição corporal (Figura 2), mas, ao final do período de utilização das pastagens, as novilhas que receberam suplemento foram mais pesadas, mais altas e apresentaram melhor escore de condição corporal $(\mathrm{P}<0,05)$. $\mathrm{O}$ aumento na altura verificado para as novilhas que receberam suplemento foi de $10,2 \mathrm{~cm}$, enquanto novilhas exclusivamente em pastagem cresceram $7,3 \mathrm{~cm}(\mathrm{P}<0,05)$. Os animais de maior altura normalmente apresentam prolongamento no período de inflexão da curva de crescimento, retardando a maturidade e o acúmulo de gordura corporal, o que pode refletir em maior idade à puberdade (De Nise \& Brinks, 1985).

A maior taxa de ganho obtida para as novilhas que receberam suplemento permitiu que a relação peso corporal:altura fosse semelhante $(\mathrm{P}>0,05)$ entre os grupos em mesma idade. A partir desta relação, pode-se concluir que os animais apresentaram a mesma estrutura corporal (Fox et al., 1988). A relação peso corporal:altura média de 2,4 observada nas novilhas ao final do período de utilização das pastagens foi semelhante ao valor de $2,53 \mathrm{~kg} / \mathrm{cm}$, considerada por Fox et al. (1988) como adequado para manifestação da puberdade.

O maior escore de condição corporal dos animais que receberam suplemento $(\mathrm{P}<0,05)$ ao final do período de pastejo é determinado pela composição do ganho de peso com maior proporção de gordura. Todas as novilhas, no entanto, atingiram o escore de condição corporal mínimo de 3,0 para que manifestem a puberdade e possam ter condições de ser acasaladas (Rocha \& Lobato, 2002). Animais recebendo suplemento energético em pastagens com elevado teor de proteína bruta tendem a acumular gordura mais precocemente em relação aqueles exclusivamente em pastejo, como resultado das elevadas relações de proteína e energia nos nutrientes consumidos (Poppi \& McLennan, 1995). A diferença de 0,1 ponto no 
escore de condição corporal (1-5) em favor das novilhas que receberam suplemento pode ser atribuído à menor deposição de tecido adiposo em animais jovens que tenham passado por restrição alimentar anterior ao período experimental (Rocha et al., 2007), favorecendo o desenvolvimento muscular. A mudança de 0,1 ponto no escore de condição corporal correspondeu a $16,6 \mathrm{~kg}$ de peso corporal. No caso de raças de corte europeias, a mudança de uma unidade no escore de condição corporal de vacas adultas, numa escala de 1 a 5 pontos, equivale a uma mudança de 60 a $80 \mathrm{~kg}$ de peso corporal (Swecker, 1997).

O peso médio das novilhas com 7-8 meses de idade no início da utilização das pastagens de ciclo hibernal correspondeu a 35,8\% do peso adulto. Admitindo o tempo médio de utilização das pastagens de 118 dias (Tabela 2), o ganho médio observado não seria suficiente (Tabela 6) para acasalamento aos 14-15 meses de idade, pois correspondeu a 18,8 e $22,8 \%$ do peso adulto, respectivamente, para as novilhas sem e com suplementação. Esses percentuais, somados ao peso inicial, não foram suficiente para atingir os $65 \%$ do peso adulto. Embora o peso corporal inicial médio seja considerado satisfatório para essa categoria, Rocha \& Lobato (2002) recomendam percentual mínimo de $40 \%$ em relação ao peso adulto por ocasião do desmame para acasalamento aos 14-15 meses de idade.

Novilhas que receberam suplemento apresentaram peso corporal final de $263,2 \mathrm{~kg}$. Admitindo-se um peso adulto de $450 \mathrm{~kg}$ para estas fêmeas e acasalamento aos 14-15 meses de idade com $65 \%$ do peso adulto, teriam sido necessários ganhos adicionais de 6,5 e 10,2\% para os grupos com e sem suplemento, respectivamente. Com a permanência dos animais com as mesmas taxas de ganho por um período maior de tempo, o peso-alvo seria atingido em 31 dias pelas fêmeas sob suplementação e em 60 dias pelas demais. Entretanto, para lograr bons índices de prenhez ao primeiro acasalamento, o peso-alvo para manifestar a puberdade deve ser atingido ao início do período de acasalamento, que ocorre em meados de novembro, conforme observado por Rocha \& Lobato (2002), o que inviabilizaria o acasalamento das fêmeas sob suplementação aos 14-15 meses de idade. As fêmeas que receberam suplemento apresentaram ao final do período experimental superioridade de 3,7\% no peso corporal final. Rocha \& Lobato (2002), trabalhando com novilhas Hereford e mestiças Hereford $\times$ Nelore, encontraram diferença de $21 \mathrm{~kg}$ de peso corporal entre prenhes e falhadas, sendo que as prenhes apresentavam 248,4 kg ao início do acasalamento.

Os ganhos obtidos pelas novilhas neste estudo foram superiores aos preconizados por Fox et al. (1988) para acasalamento aos 14-15 meses de idade, mas não foram suficientes para determinar o peso adequado para manifestação da puberdade. O peso corporal das novilhas à desmama, associado ao sistema alimentar a ser utilizado na pós-desmama, constitui a principal ferramenta da tomada de decisão para decidir a idade do primeiro acasalamento das fêmeas. Para que o peso-alvo pudesse ser atingido ao início da estação de acasalamento, as novilhas deveriam apresentar, ao início do período de utilização das pastagens, 40,4 e 44,9\% do peso adulto, respectivamente, em pastagem com e sem suplemento.

\section{Conclusões}

Os teores de matéria seca e fibra em detergente neutro na forragem consumida em pastagens cultivadas de clima frio não limitam a ingestão de matéria seca por novilhas recebendo ou não suplemento. $\mathrm{O}$ uso de suplementos concentrados para novilhas de corte em pastagem de clima frio pode ser uma estratégia para aumentar o ganho de peso individual e por unidade de área, caracterizando relações de adição e substituição do consumo de suplemento e do consumo de pasto. Quando pastagens de azevém e aveia são manejadas com massa de forragem entre $1.200 \mathrm{e}$ $1.500 \mathrm{~kg} / \mathrm{ha}$ de matéria seca, a altura do dossel, o teor de proteína bruta e a digestibilidade da forragem aparentemente consumida pelos animais em pastejo não são alterados pelo uso de suplementos concentrados. Ao final do período de utilização das pastagens de clima frio, novilhas sob suplementação apresentam maior altura e melhor escore de condição corporal e peso corporal, condições que permitem o acasalamento com menor idade.

\section{Referências}

ALBERTO, E. Efectos de la calidad de los forrajes y la suplementacion em el desempeno de rumiantes em pastoreo. In: SIMPÓSIO SOBRE AVALIAÇÃO DE PASTAGENS COM ANIMAIS, 1997, Maringá. Anais... Maringá: Cooper Graf. Artes Gráficas Ltda, 1997. p.53-73.

ASSOCIATION OF OFFICIAL ANALYTICAL CHEMISTS - AOAC. Official methods of analysis. 14.ed. Washington, 1995. 1141p.

ASTIGARRAGA, L. Tecnicas para la medición del consumo de ruminantes en pastoreo. In: SIMPÓSIO SOBRE AVALIAÇÃO DE PASTAGENS COM ANIMAIS, 1997, Maringá. Anais... Maringá: Cooper Graf. Artes Gráficas Ltda, 1997. p.1-23.

BARGO, F.; MULLER, L.D.; KOLVER, E.S. et al. Invited review: production and digestion of supplemented dairy cows on pasture. Journal of Dairy Science, v.86, n.4, p.1-42, 2003.

BEEVER, D.E.; THOMSON, D.J.; ULYATT, M.J. et al. The digestion of fresh perennial ryegrass ( Lolium perenne vs. Melle) and white clover ( Trifolium repens cv. Blanca) by growing cattle fed indoors. British Journal of Nutrition, v.54, n.3, p.763-775, 1985.

BEEVER, D.E.; THORP, C.L. Supplementation of forage diets. In: WELCH, R.A.S.; BURNS, D.J.W.; DAVIS, S.R. et al. (Eds.) 
Milk composition, production and biotechnology. Oxon: CAB International, 1997. 419p.

BREMM, C.; ROCHA, M.G.; RESTLE, J. et al. Efeito de níveis de suplementação sobre o comportamento ingestivo de bezerras em pastagem de aveia (Avena strigosa Schreb.) e azevém (Lolium multiflorum Lam.). Revista Brasileira de Zootecnia, v.34, n.2, p.387-397, 2005.

BREMM, C.; ROCHA, M.G.; FREITAS, F.K. et al. Comportamento ingestivo de novilhas de corte submetidas a estratégias de suplementação em pastagens de aveia e azevém. Revista Brasileira de Zootecnia, v.37, n.7, p.1161-1167, 2008.

CATON, J.S.; DHUYVETTER, D.V. Influence of energy supplementation on grazing ruminants: requeriments and responses. Journal of Animal Science, v.75, n.2, p.533-542, 1997

CLARK, D.A.; KANNEGANTI, V.R. Grazing management systems for dairy cattle. In: CHERNEY, J.H.; CHERNEY, D.J.R. (Eds.) Grass for dairy cattle. Oxon: CAB International, 1998. p.331.

COIMBRA, J.L.M.; CARVALHO, F.I.F.; OLIVEIRA, A.C. Fundamentos do SAS aplicado à experimentação agrícola. Pelotas: UFPEL, 2004. 246p.

DE NISE, R.S.K.; BRINKS, J.S. Genetic and environmental aspects of the growth curve parameters in beef cows. Journal of Animal Science, v.61, n.5, p.1431-1443, 1985

DIXON, R.M.; STOCKDALE, C.R. Associative effects between forages and grains: consequences for feed utilization. Australian Journal of Agricultural Research, v.50, p.757-773, 1999.

ELIZALDE, J.C. Suplementacion en condiciones de pastoreo. In: JORNADA DE ACTUALIZACIÓN GANADERA, 1., 2003, Balcarce. Anais... Balcarce: INTA Balcarce, 2003. p.17-28.

FERNÁNDEZ, E.; MIERES, J. Algunos conceptos sobre el uso de suplementos en los sistemas invernadores. In: JORNADA PRODUCCION ANIMAL INTENSIVA. INIA La Estanzuela, Colonia, 2005. p.1-10. (Serie de Actividades de Difusión $\mathrm{N}^{\circ}$ 406).

FOX, D.G.; SNIFFEN, C.J.; O'CONNOR, J.D. Adjusting nutrient requirements of beef cattle for animal and environmental variations. Journal of Animal Science, v.66, n.6, p.1475-1495, 1988.

FREITAS, F.K.; ROCHA, M.G.; RESTLE, J. et al. Suplementação energética na recria de fêmeas de corte em pastagem cultivada de inverno. Dinâmica da pastagem. Revista Brasileira de Zootecnia, v.34, n.6, p.2029-2038, 2005a.

FREITAS, F.K.; ROCHA, M.G.; RESTLE, J. et al. Suplementação energética na recria de fêmeas de corte em pastagem cultivada de inverno. Produção animal. Revista Brasileira de Zootecnia, v.34, n.4, p.1256-1266, 2005b

FRENCH, P.; MOLONEY, A.P.; O'KIELY, P. et al. Growth and rumen digestion characteristics of steers grazing autumn grass supplemented with concentrates based on different carbohydrate sources. Animal Science, v.72, p.139-148, 2001a.

FRENCH, P.; O’RIORDAN, E.G.; O’KIELY, P. et al. Intake and growth of steers offered different allowances of autumn grass and concentrates. Animal Science, v.72, p.129-138, 2001. 2001b.

FRIZZO, A.; ROCHA, M.G.; RESTLE, J. et al. Produção de forragem e retorno econômico da pastagem de aveia e azevém sob pastejo com bezerras de corte submetidas a níveis de suplementação energética. Revista Brasileira de Zootecnia, v.32, n.3, p.632-642, 2003a

FRIZZO, A.; ROCHA, M.G.; RESTLE, J. et al. Suplementação energética na recria de bezerras de corte mantidas em pastagem de inverno. Revista Brasileira de Zootecnia, v.32, n.3, p.643-652, 2003b.

GIBB, M.J.; TREACHER, T.T. The effect of herbage allowance on herbage intake and performance of lambs grazing perennial ryegrass and red clover swards. Journal of Agricultural Science, v.86, p.355-365, 1976.
GOERING, H.K.; VAN SOEST, P.J. Forage fiber analysis (apparates, reagents, procedures and some applications). USDA Agricultural Research Service, 1970. (Handbook, 379).

HODGSON, J. Grazing management: science into practice. London: Longman Scientific \& Technical, 1990. 203p.

HODGSON, J.; BROOKES, I.M. Nutrition of grazing animals. In WHITE, J.; HODGSON, J. (Eds.) Pasture and crop science. Auckland: Oxford University Press, 1999. p.117.

HORN, G.W.; BECK, P.A.; ANDRAE, J.G. et al. Designing supplements for stocker cattle grazing wheat pasture. Journal of Animal Science, v.83, n.13, p.E69-E78, 2005.

INSTITUTO BRASILEIRO DE GEOGRAFIA E ESTATÍSTICA IBGE. Levantamento sistemático da produção agrícola. v.18, n.1, p.1-76, 2007.

LEMENAGER, R.P.; SMITH, W.H.; MARTIN, T.G. et al. Effects of winter and summer energy levels on heifers growth and reproductive performance. Journal of Animal Science, v.51, n.5, p.837-842, 1980.

MACARI, S.; ROCHA, M.G.; PÖTTER, L. et al. Comportamento ingestivo diurno de novilhas de corte recebendo níveis de suplemento. Ciência Rural, v.37, n.6, p.1746-1752, 2007.

MERTENS, D.R. Análise da fibra e sua utilização na avaliação de alimentos e formulação de rações. In: SIMPÓSIO INTERNACIONAL DE RUMINANTES, REUNIÃO ANUAL DA SOCIEDADE BRASILEIRA DE ZOOTECNIA, 29., 1992, Lavras. Anais... Lavras: Sociedade Brasileira de Zootecnia, 1992. p.188-219.

MINSON, D.L. Forage in ruminant nutrition. San Diego: Academic Press, 1990. 483p.

MOORE, J.E.; BRANT, M.H.; KUNKLE, W.E. et al. Effects of supplementation on voluntary forage intake, diet digestibility, and animal performance. Journal of Animal Science, v.77, n.S2, p.122-135, 1999 .

NATIONAL RESEARCH COUNCIL - NRC. Nutrient requirements of beef cattle. 7.ed. Washington D.C.: National Academy Press, 1996. 248p.

PILAU, A.; ROCHA, M.G.; RESTLE, J. et al. Desenvolvimento de novilhas de corte recebendo ou não suplementação energética em pastagem com diferentes disponibilidades de forragem. Revista Brasileira de Zootecnia, v.34, n.5, p.1483-1492, 2005a.

PILAU, A.; ROCHA, M.G.; RESTLE, J. et al. Produção de forragem e produção animal em pastagem com duas disponibilidades de forragem associadas ou não à suplementação energética. Revista Brasileira de Zootecnia, v.34, n.4, p.1130-1137, 2005b.

PILAU, A.; ROCHA, M.G.; RESTLE, J. et al. Recria de novilhas de corte com níveis de suplementação energética em pastagem de aveia preta e azevém. Revista Brasileira de Zootecnia, v.33, n.6, p.2104-2113, 2004.

POPPI, D.P.; McLENNAN, S.R. Protein and energy utilization by ruminants at pasture. Journal of Animal Science, v.73, n.1, p.278-290, 1995.

RECOMENDAÇÕES DE ADUBAÇÃO E CALAGEM PARA OS ESTADOS DO RIO GRANDE DO SUL E SANTA CATARINA ROLAS. 3.ed. Passo Fundo: SBCS-Nucleo Regional Sul, 1994. 223p.

RICE, L.E. Nutrition and the development of replacement heifers. Veterinarian Clinics of North America, v.7, n.1, p.27-42, 1991.

ROCHA M.G.; POTTER, L.; ROSO, D. et al. Sistemas intensivos de produção de gado de corte - ênfase na recria de fêmeas. In: GOTTSCHALL, C. (Ed.) CICLO DE PALESTRAS EM PRODUÇÃO E MANEJO DE BOVINOS, 12., 2007, Canoas. Anais... Canoas: ULBRA, 2007. p.100-120.

ROCHA, M.G.; LOBATO, J.F.P. Sistemas de alimentação pósdesmama de novilhas de corte para acasalamento com 14/15 
meses de idade. Revista Brasileira de Zootecnia, v.31, n.4, p.1814-1822, 2002.

ROCHA, M.G.; PILAU, A.; SANTOS, D.T. et al. Desenvolvimento de novilhas de corte submetidas a diferentes sistemas alimentares. Revista Brasileira de Zootecnia, v.33, n.6, p.2123-2131, 2004.

ROCHA, M.G.; RESTLE, J.; FRIZZO, A. et. al. Alternativas de utilização da pastagem hibernal para recria de bezerras de corte. Revista Brasileira de Zootecnia, v.32, n.2, p.383-392, 2003.

ROSA, A.N.; ROCHA, M.G.; ROSO, D. et al. Diferentes freqüências de suplementação para bezerras em pastagem de azevém. In: REUNIÓN DEL GRUPO TECNICO EM FORRAGERAS DEL CONO SUR - GRUPO CAMPOS, 22., 2008, Minas. Anais... Minas - Uruguay: Grupo Campos, 2008a.

ROSA, A.N.; ROCHA, M.G.; ROSO, D. et al. Recria de bezerras de corte em pastagem de azevém sob freqüências de suplementação. In: REUNIÃO ANUAL DA SOCIEDADE BRASILEIRA DE ZOOTECNIA, 45., 2008, Lavras. Anais... Lavras: UFLA, 2008b.

ROSO, D.; ROCHA, M.G.; PÖTTER, L. et al. Recria de bezerras de corte em alternativas de uso da pastagem de azevém (Lolium multiflorum Lam.). Revista Brasileira de Zootecnia, v.38, n.2, p.240-248, 2009.
SANTOS, D.T.; ROCHA, M.G.; GENRO, T.C.M. et al. Suplementos energéticos para recria de novilhas de corte em pastagens anuais. Análise econômica. Revista Brasileira de Zootecnia, v.33, n.6, p.2359-2368, 2004.

SANTOS, D.T.; ROCHA, M.G.; QUADROS, F.L.F. et al. Suplementos energéticos para recria de novilhas de corte em pastagens anuais. Desempenho animal. Revista Brasileira de Zootecnia, v.34, n.1, p.209-219, 2005.

STATISTICAL ANALYSIS SYSTEM - SAS. Statistical analysis system user's guide: statistics. Version 8.2, Cary: SAS Institute, 2001. 1686p.

ST-PIERRE, N.R. Integrating quantitative findings from multiple studies using mixed model methodology. Journal of Dairy Science, v.84, n.4, p.741-755, 2001.

SWECKER, W.S. Effects of nutrition on reproductive performance of beef cattle. In: YOUNGQUIST, R.S. (Ed.) Current therapy in large animal theriogenology. Philadelphia: Saunders, 1997. p.423-428.

TILLEY, J.M.A.; TERRY, R.A. A two-stage technique for the "in vitro" digestion of forage crop. Journal of British Grassland Society, v.18, n.2, p.104-111, 1963.

VAN SOEST, P.J. Nutritional ecology of the ruminant. 2.ed. Ithaca: Cornell University Press, 1994. 476p. 